\title{
Integrating Information Literacy Training in an English- Speaking Course in the Chinese Context
}

\author{
Kezhen Liu ${ }^{1, *}$, Andrew Lian ${ }^{1}$, Butsakorn Yodkamlue ${ }^{1}$ \\ ${ }^{1}$ Suranaree University of Technology, Thailand 1 \\ *Kezhen Liu.E-mail: Jen.l.k@foxmail.com
}

\begin{abstract}
This study investigated the effects of a teaching approach combining information literacy training and an ongoing roleplaying game to improve Chinese university students' English-speaking skills and strengthen their sense of learner autonomy. The study employed a quasi-experimental design. Two intact classes, altogether 85 college students, participated in the study. One class was randomly assigned as the experimental group and the other as the control group. Both groups participated in an English-Speaking Course (ESC), a compulsory course taught by teachers who were native English speakers. The approach was administered to the experimental group for 11 weeks. The control group participated in a traditional ESC, also for 11 weeks. The same teacher taught both groups. The findings revealed that after 11 weeks' intervention, the experimental group improved their English-speaking skills and strengthened their sense of learner autonomy significantly, while the control group made no significant improvement in the two variables. The approach was considered innovative, challenging, and effective by the experimental group students. Moreover, the students indicated that they became more confident and motivated to learn to speak English. Meanwhile, the training lesson made them realize the benefits that technology devices can bring to their learning.
\end{abstract}

Keywords: Information literacy training, English-speaking course, learner autonomy.

\section{INTRODUCTION}

According to statistics, the number of Chinese who learn English as a Foreign Language (EFL) has reached 400 million in recent years [1]. English is normally taught as a compulsory course from grade three in primary schools in China. With the pressure of enrollment, students at all levels are basically taking English learning as seriously as the core of their study. The same is true of the parents, who keep sending their children to different kinds of training institutes or hiring private tutors for them as long as they can afford it. However, the result of these efforts is not satisfactory when it comes to the application of English in realworld communication. More than a decade ago, most Chinese students started to refer to themselves as the product of "mute English education" [2]. According to the Guangmin Daily, there were 9.6 million students taking College English Test Band 4 (CET4) or Band 6 (CET6) in the first half of 2017. Nevertheless, many students who had high scores in CET4 or CET6 were found to be incompetent in communicating in English.

Noticing the unsatisfactory situation, the Chinese Ministry of Education published requirements for the college English curriculum in 2007, saying that "the objective of college English is to develop students' ability to use English in a well-rounded way, especially in listening and speaking, so that in their future studies and careers as well as social interactions they will be able to communicate effectively, and at the same time enhance their ability to study independently..." In response to the curriculum requirements, more and more universities and colleges have set up English-Speaking Course (ESC) for English majors and many of the nonEnglish majors. In the beginning, the ESC was more like an experimental course for some universities to explore effective ways to develop students' Englishspeaking skills [3]. A few years later, it gradually became a compulsory course for English some of nonEnglish majors. The ESC is taught by Native Speakers of English (NSE) in an attempt to create an authentic English-speaking environment for the students. However, although it is a compulsory course taught by NSE teachers, it has been reported to be less effective than expected due to the institutes and NSE teachers' lack of adequate, relevant pedagogic experience [4]. Students feel relaxed in such a classroom. Nevertheless, 
the course fails to help them improve their Englishspeaking skills significantly in general.

\section{LITERATURE REVIEW}

\subsection{Studies on ESC}

Many studies have been conducted to investigate ESC classrooms' situation in an attempt to identify the problems and make them more effective. For example, Tang et al. [3] designed and implemented a large-scale instructional experiment to test the possibility and effects of offering an ESC (in their study, they translated the course name into Oral English Course) to students who had a certain level of English proficiency and motivation to improve their English-speaking skills. This experiment's main goal was to find out possible problems that might be encountered in an ESC classroom. They used observation, student diaries, questionnaires, and interviews to collect data. The data findings showed that most of the students had respect for the NSE teachers and got motivation from them, but they did not agree that they had improved their Englishspeaking skills significantly after taking the ESC.

Besides published articles, many theses on ESC took the same or similar research methodology to investigate similar topics: the characteristics of ESC and NSE teachers' teaching; students and NSE teachers' perceptions of ESC; problems in ESC classrooms, etc. They mostly used questionnaires, observation, students' diaries, interviews, or a combination of those to collect data, then analyzed and discussed the findings, and finally gave suggestions on how to solve the problems and make the ESC classrooms more effective for students' development of English-speaking skills. For example, Zhang's thesis [4] used a questionnaire and interview to investigate 300 university students and 3 NSE teachers' perceptions of the ESC classrooms. In the findings, it was shown that the ESC lessons attracted students' attention easily at the beginning since the NSE teachers naturally were a sign of authentic language environment and motivation. However, with more time spent taking the course, students' interest decreased.

The above findings echo some other studies' findings. As Xiao [5] argues, like a two-sided coin, the NSE teachers motivate students, but at the same time, they bring up some problems due to different cultural backgrounds. In China, teachers always have clearly predefined teaching objectives and uniformly standard textbooks for their teaching, but the NSE teachers preferred to do their teaching flexibly without standard textbooks nor clear objectives [5]. It is not saying that the only appropriate teaching approach for the Chinese students has to be constructed by predefined teaching and learning objectives together with standard textbooks, but changes and reforms should take place step by step, leaving students some space to adapt. The
NSE teachers' flexibility and relaxing style, reflected in sudden changes of direction suddenly, does win students' appreciation and motivate them at the beginning, yet students usually lose their interest and come back to their passive and obedient mode after a period of time. Due to the cultural issues, Chinese students are do not find it easy to learn in a completely autonomous environment nor from a teacher without a clear, systematic, and published teaching sequence. Nonetheless, the history of the ESC in China is not long enough to make course arrangements, teacher's roles, and course objectives clear and sufficiently detailed [6]. Consequently, the ESC has always been less effective than it was expected to be.

\subsection{Information Literacy Training}

In the era of technology and information, plenty of researchers have pointed out the significance of learner training on developing learners' skill base to use technology effectively [7]. However, if any, few have realized the potential of learner training on developing learners' skill base to locate, evaluate, and use different sources of information via the Internet effectively and efficiently to enable better learning and make better decisions. Early in 2005, Breivik points out that today's young generation with easy access to diverse information from mobiles, computers, and other technology devices often depend for their schoolwork and information needs on the Internet [8]. This phenomenon clearly leads to the concern as to whether these young people can evaluate the reliability and validity of the information they encounter and whether they can make the most of the information convenient. It brings to the ability to recognize whenever there is an information gap and then locate, evaluate, and use the needed information effectively to solve problems at hand, which is recognized as Information Literacy (IL) by the field of Libraries and Information Science [9].

Based on empirical evidence, being information literate positively influences lifelong learning [10] and better classroom performance [11]. According to Šorgo et al. [12], a broad spectrum of IL skills promotes higher cognitive levels of thinking and more systematic learning. As a result, learner training on IL skills is significant for students to learn better and perhaps succeed in the future. Nonetheless, as more and more people choose the Internet over libraries to gather information, IL training in technology contexts could be a better focus not just because the Internet has become a dominant source of information but also because the library has librarians as the gatekeepers to information whereas the Internet does not.

As the future trends of language markets are unpredictable and changeable [13], let alone the evolving nature of language itself, language learners especially need to be trained in IL skills in technological 
contexts. Take English as an example, with abundant new words coming out of the Internet and new inventions every day, English tomorrow might not be the same as English today. Consequently, learning from teachers in the classroom passively is not enough for the students to master communicative English. A combination of classroom teaching with learning activities outside the classroom could produce more effective learning and enable foreign language learning to become a process of learner autonomy development [14]. Not to mention that one will never know for what purposes he or she is going to use English and whom to talk with. As a result, English as a Foreign Language (EFL) or English as a Second Language (ESL) learners especially needs to keep up with the changes [15] and be prepared to face the uncertainty. To do so, it is significant to integrate IL training with technology in foreign language classrooms.

Considering the problems of ESC mentioned earlier and the significance of IL training in language education, a new approach for ESC was designed based on the combination of IL training and practice in technological devices (mobiles, PC, etc.) and an ongoing role play game as language environment for students to practice their English-speaking skills. The approach took Xiao [5]'s suggestions into consideration, designed three sequential tasks to give the students a certain level of control and freedom to some extent. Students' technological devices were used for IL training and practice in the study because they are the uniquely suited to supporting language learning on an ongoing basis and enabling selection of affordable learning materials to meet students' different learning needs [15]. An 11-week experiment was designed and conducted so as to explore the potential of this approach as the optimizer of ESC classroom practice.

This paper addresses the following questions:

1. How does the intervention influence the effects of ESC classroom practice?

2. How do the students perceive and react to the intervention?

\section{METHODS}

The study applied a quasi-experimental design. By implementing an 11-week pedagogic intervention in one of two homogeneous ESC classrooms, the effects of the intervention can, therefore, be analyzed and interpreted clearly by comparing the two classrooms.

\subsection{Context and Participants}

The study was conducted in Qingyuan Polytechnic, which is located in a small city in southern China. One intact class of 42 second-year undergraduates majoring in Business English was assigned as the experimental group. Another intact class of 43 second-year undergraduates majoring in Business English was

Table 1. Lesson plan for the information literacy training

\section{Objectives:}

By the end of the 90-minute training lesson, students are expected to understand basically how to use their technology devices to locate, evaluate, and use information or resources effectively to facilitate learning.

\begin{tabular}{|c|c|c|c|}
\hline Themes/topics & Techniques & Time & Materials \\
\hline $\begin{array}{l}\text { Opening and } \\
\text { warming-up }\end{array}$ & $\begin{array}{l}\text { Greeting; Briefly introduce the training lesson and relevant concepts like CAL } \\
\text { and information literacy, etc., then link them together. }\end{array}$ & $15 \mathrm{mins}$ & $\begin{array}{l}\text { Video lectures; } \\
\text { computer; slides }\end{array}$ \\
\hline $\begin{array}{l}\text { Basic knowledge } \\
\text { and skills of IL and } \\
\text { the Big6 }\end{array}$ & $\begin{array}{l}\text { 1.Introduce basic knowledge and skills of IL and the Big6; } \\
\text { 2.Explain the potential of using technology devices as a platform to perform } \\
\text { IL skills and the Big6 process. }\end{array}$ & $25 \mathrm{mins}$ & $\begin{array}{l}\text { Computer; } \\
\text { projector; Slides, } \\
\text { video }\end{array}$ \\
\hline $\begin{array}{l}\text { Practice IL skills } \\
\text { using the Big6 } \\
\text { process in } \\
\text { technology devices }\end{array}$ & $\begin{array}{l}\text { 1.Select } 4 \text { volunteers to practice the Big6 to collect information and use the } \\
\text { information to perform a role play game; } \\
\text { 2. The trainer coordinates the role play game. }\end{array}$ & $20 \mathrm{mins}$ & \\
\hline $\begin{array}{l}\text { Reflection and } \\
\text { presentation }\end{array}$ & $\begin{array}{l}\text { 1.Select two volunteers to present their reflection on information } \\
\text { gathering/Big6 process; } \\
\text { 2. Give comment on the presentation and display an example of using } \\
\text { technology devices to complete tasks. }\end{array}$ & $20 \mathrm{mins}$ & $\begin{array}{l}\text { Computer; } \\
\text { Mobile phone; } \\
\text { Projector }\end{array}$ \\
\hline Q \& A & The trainer answers students' questions concerning the training. & 10mins & \\
\hline
\end{tabular}

most convenient technology for the students and 
students had similar English proficiency and similar backgrounds in learning English. The intervention was implemented with the experimental group in their ESC classroom for a duration of 11 weeks. Both the experimental group and the control group needed to take ESC as a compulsory course when the experiment was conducted. They were taught by the same NSE teacher from America. The difference was that the experimental

needed information/resources via their technological devices to assist their learning.

The training lesson on IL was designed and implemented based on Eisenberg [16]'s Big6 Approach: step 1. Task definition (define the problem and identify the information needed); step 2. Information seeking strategies (determine all possible sources and select the best sources); step 3. Location and cess (locate sources and find formation within sources); step 4. se of information (engage and tract relevant information); step Synthesis (organize information om multiple sources and present formation); step 6. Evaluation ldge the result and process, i.e., fectiveness and efficiency). Table presents an outline of the lesson an for the training lesson on IL.

Activity1(any places): teammates discuss how to develop the story based on the previous story for the role play game; figure out information needs regarding one's role; locate/gather information; discuss how to act and interact in the role play game Activity2(classroom): act out role play game team by team Activity3(classroom): write reflection report

Lesson 3

Activity1(any places): teammates discuss how to develop the story based on the previous story for the role play game; figure out information needs regarding one's role; locate/gather information; discuss how to act and interact in the role play game Activity2(classroom): act out role play game team by team Activity3(classroom): write reflection report

group's classroom was intervened with the new approach characterized by IL training and practice while the control group's classroom remained with no changes. Taught one lesson per week, 90 minutes for each lesson, the main purposes of this course were to help students improve their English-speaking skills and their ability to study independently.

\subsection{Pedagogic Procedure}

Students in the control group had ESC lessons for 11 weeks with traditional routines as other classes did. The routines for a traditional ESC lesson are normally as follows: an NSE teacher appears in the classroom without a lesson plan or textbook, speaking in English, showing different cultures, telling fun stories, having students discuss among themselves under given topics, using random activities to interact with students, assigning basically no homework, etc. [3.5]. However, students in the experimental group had a training lesson in the first week on how to locate, evaluate, and use
After the first week's training sson, students in the experimental oup needed to complete three quential tasks in each of the maining 10-week's lessons: 1 . se their own technological vices to practice IL skills to find formation/resources for the next sk (45 minutes) in any place of eir choice (not necessary to attend e classroom); 2. Perform a ntinuous, ongoing role play game English, using the information/resources from Task 1 (35 minutes, in the classroom); 3. Write a small report on the information/resources used (10 minutes, in the classroom). Figure 1 presents the experimental group's pedagogic procedures in the remaining 10 weeks (one lesson per week).

\subsection{Data Collection and Analysis}

The study data were collected from pretest and posttest of English-speaking skills, a questionnaire concerning learner autonomy, a questionnaire concerning students' perceptions and reactions, and semi-structured interviews. As mentioned, the foremost purposes of ESC are to improve students' English-speaking skills and develop their ability to learn independently. To examine the intervention's effects in achieving the two objectives, a pretest and a posttest of English-speaking skills and a questionnaire concerning students' sense of learner autonomy were constructed and administered to both groups before and after the experiment, respectively. To collect data regarding students' perceptions and reactions concerning the intervention, a questionnaire was constructed and administered to the 
experimental group students at the end of the experiment. To elicit in-depth information regarding students' perceptions and reactions, as well as the development of their sense of learner autonomy, semistructured interviews were conducted at the end of the experiment.

\section{FINDINGS AND DISCUSSION}

Findings are presented and discussed according to the two research questions the current study addresses, namely "How does the intervention influence the effects of ESC classroom practice?" and "How do the students perceive and react to the whole intervention?"

\subsection{How does the intervention influence the effects of ESC classroom practice?}

The foremost course objectives for the ESC, i.e., improving students' English-speaking skills and developing their ability to learn independently, were two main dependent variables for the current study. Therefore, the two variables were used to measure and discuss the effects of the intervention on ESC classroom practice.

\subsubsection{English-speaking Skills}

To measure the effects of the intervention in achieving one of the course objectives - improving students' English-speaking skills, a pretest and a posttest of English-speaking were developed based on the IELTS speaking test format. The rating rubric was based on the IELTS' band descriptors for Englishspeaking. It consisted of four elements of speaking, namely fluency and coherence, lexical resource, grammar range and accuracy, and pronunciation. Each element took up 25 points; therefore the full score of the test was 100 points.

According to the results from the pretest, the experimental group had a mean score $(\bar{x}=68.42)$ lower than that of the control group ( $\bar{x}=70.11)$ in the pretest, but not statistically different $(\mathrm{p}=0.490)$. This indicates that the two groups of students had homogeneous English-speaking skills before the experiment. The posttest experimental group ( $\bar{x}=75.35$ ) outperformed the control group ( $\bar{x}=71.41 ; p=0.043)$. Moreover, there was a statistically significant difference between mean scores of the pretest and the posttest for the experimental group $(\mathrm{p}=0.000)$, indicating that students in the experimental group had improved their performance in English-speaking skills significantly after 11 weeks of intervention (improvement=6.93). However, the control group had no significant improvement within the 11 weeks ( $p=0.090$; improvement=1.30). In conclusion, after 11 weeks of pedagogic intervention, the experimental group caught up the original difference with the experimental group and went past it, significantly outperforming the control group in terms of English-speaking skills.

The standard deviation of the experimental group $(\mathrm{SD}=8.911)$ was slightly higher than that of the control group ( $\mathrm{SD}=8.745)$ but lower than its standard deviation in the pretest $(\mathrm{SD}=12.213)$. This means that after 11 weeks of pedagogic intervention, the experimental group's scores became more stable, consistent, and regularly distributed along with the mean score. The same is true of the control group, whose standard deviation decreased by 1.392 from the pretest $(\mathrm{SD}=10.137)$ to the posttest $(\mathrm{SD}=8.745)$. Similarly, it indicates that the control group scores became more stable, consistent, and regularly distributed along with the mean score, although their improvement was not significant.

The pretest and the posttest showed that the experimental intervention was more effective than the traditional ESC classroom in helping students improve their English-speaking skills the foremost objective of the course. The improvement might be the second task's direct effects, which required students to attend the classroom and perform a continuous, ongoing role play game with their teammates. The task was designed to create an environment for the students to practice English-speaking skills and to bring out information gaps for Task 1. This environment, referred to as a macrosimulation by Lian and Mestre [17], simulates the real-world situations that the students may encounter soon. In these real-world simulations, students can safely practice their English-speaking skills. As Illés and Akcan [18] put it, creating a safe environment for the students to speak English on topics of interest involved students' own realities and made them speak English spontaneously. Consequently, the ongoing role play game as a safe environment for speaking English had direct effects on advancing students' Englishspeaking skills.

Besides the ongoing role play game during which students actually spoke English, the IL practice in Task 1 and the reflection report in Task 3 helped the students with their English-speaking skills indirectly and enabled long-term and better learning. Theoretically, Task 1 covered different aspects that promote effective and autonomous learning [19], including cognitive aspects (finding and knowing different learning materials and information); metacognitive aspects (evaluating and selecting learning materials and information); and affective aspects (finding learning materials and information based on their own interests and motivation). Task 2 (the ongoing role play game) covered the action-oriented aspects, which made sure every student actually spoke English for a 
comparatively equal amount of time. Task 3 (reflection report) was, in fact, a reflection on mostly Task 1 and partially Task 2, designed in an attempt to let the students see the big picture of the whole set of ESC lessons and their performance in each lesson clearly to provide them with the opportunity to improve lesson by lesson. This added to the fact that the three tasks all set the students free to different extents so that they could have room to learn autonomously and develop their own intrinsic motivation gradually. These all counted for students' improvements in terms of English-speaking skills.

\subsubsection{Learner Autonomy}

\subsubsection{Questionnaire}

In order to explore the intervention's effects on students' ability to learn independently, a questionnaire was constructed based on Tassinari [19]'s model to evaluate students' levels of agreement on the questions regarding learner autonomy and their ability to learn independently. To offset the limitation of the closedended questionnaire, questions related to the development of students' sense of learner autonomy and their ability to learn independently during the experiment were explored in the form of semi-structured interviews.

The questionnaire for students' sense of learner autonomy was administered to the experimental group and the control group before and after the experiment, respectively. The questionnaire used 5-point Likertscale questions ranging from strongly disagree, disagree, undecided, agree, to strongly agree, to make clear distinctions between students' levels of agreement with the statements. In scoring students' responses, 1 point was assigned to strongly disagree, 2 to disagree, 3 to undecided, 4 to agree, and 5 to strongly agree. A higher score indicated students' stronger agreement with the corresponding item of the maximum score on the 10 items of the scale was 50 points.
The data collected from the scale administered before the experiment showed that there was no significant difference between the means for the experimental group ( $\bar{x}=31.80, S D=2.839)$ and the control group ( $\bar{x}=31.97, S D=1.854)$ with a $p$-value higher than $0.05(\mathrm{p}=0.779)$. The data collected from the scale administered after the experiment showed that there was a statistically significant difference between the means for the experimental group ( $\bar{x}=35.50$, $\mathrm{SD}=2.432)$ and the control group $(\overline{\mathrm{x}}=33.02, \mathrm{SD}=3.474)$ with a $\mathrm{p}$-value lower than $0.05(\mathrm{p}=000)$. This is to say that students in the two groups had homogeneous levels of learner autonomy before the experiment. After the experiment, however, students in the experimental group had a level of learner autonomy that was significantly higher than that of students in the control group. Moreover, the results also revealed a significant difference between the mean scores of students' learner autonomy before the experiment and after the experimental group experiment $(\mathrm{p}=.000, \mathrm{t}(41)=-6.387)$. This is to say that the experimental group students had improved their sense of learner autonomy significantly after 11 weeks of pedagogic intervention. The control group did not achieve significant improvement in their sense of learner autonomy during the 11 weeks $(\mathrm{p}=.066$, $\mathrm{t}(42)=-1.887)$.

Table 2 presents each item's descriptive statistics on the Likert-scale of students' learner autonomy before the experiment and after the experiment for the experimental group. It can be seen from the table that the mean of each item had increased to different extents after the experiment. Especially, the mean of Item 1 concerning students' ability to evaluate their Englishspeaking skills, had increased greatly from 2.71 points before the experiment to 3.71 points after the experiment. Item 3 concerning students' ability to consult teachers or co-learners to evaluate their proficiency and learning methods concerning Englishspeaking skills had a mean of 2.61 points before the experiment and 3.11 points after the experiment. These results indicate that after 11 weeks of the experiment, students became better at evaluating their proficiency in English-speaking. 
Table 2. Descriptive statistics of the Likert-scale questions

\begin{tabular}{|c|c|c|c|c|}
\hline Items & & $\mathbf{N}$ & $\overline{\mathbf{x}}$ & SD \\
\hline 1. I can autonomously evaluate my English-speaking skills. & $\begin{array}{l}\text { Before } \\
\text { After }\end{array}$ & $\begin{array}{l}42 \\
42\end{array}$ & $\begin{array}{l}2.71 \\
3.71\end{array}$ & $\begin{array}{l}0.969 \\
0.708\end{array}$ \\
\hline 2. I can practice English-speaking skills with others on my own initiative. & $\begin{array}{l}\text { Before } \\
\text { After }\end{array}$ & $\begin{array}{l}42 \\
42\end{array}$ & $\begin{array}{l}2.83 \\
3.50\end{array}$ & $\begin{array}{l}0.695 \\
0.707\end{array}$ \\
\hline $\begin{array}{l}\text { 3. I can ask teachers or co-learners to evaluate my proficiency and learning methods } \\
\text { of English-speaking skills. }\end{array}$ & $\begin{array}{l}\text { Before } \\
\text { After }\end{array}$ & $\begin{array}{l}42 \\
42\end{array}$ & $\begin{array}{l}2.61 \\
3.11\end{array}$ & $\begin{array}{l}0.794 \\
0.739\end{array}$ \\
\hline 4. I can make study plans for learning English-speaking skills. & $\begin{array}{l}\text { Before } \\
\text { After }\end{array}$ & $\begin{array}{l}42 \\
42\end{array}$ & $\begin{array}{l}3.14 \\
3.54\end{array}$ & $\begin{array}{l}0.783 \\
0.771\end{array}$ \\
\hline 5. I can practice English-speaking skills on my own. & $\begin{array}{l}\text { Before } \\
\text { After }\end{array}$ & $\begin{array}{l}42 \\
42\end{array}$ & $\begin{array}{l}3.52 \\
3.57\end{array}$ & $\begin{array}{l}0.803 \\
0.737\end{array}$ \\
\hline 6. I can recognize my motivation for learning English-speaking skills. & $\begin{array}{l}\text { Before } \\
\text { After }\end{array}$ & $\begin{array}{l}42 \\
42\end{array}$ & $\begin{array}{l}3.54 \\
3.64\end{array}$ & $\begin{array}{l}0.802 \\
0.850\end{array}$ \\
\hline 7. I am aware of my needs in learning English-speaking skills. & $\begin{array}{l}\text { Before } \\
\text { After }\end{array}$ & $\begin{array}{l}42 \\
42\end{array}$ & $\begin{array}{l}3.38 \\
3.42\end{array}$ & $\begin{array}{l}0.696 \\
0.703\end{array}$ \\
\hline 8. I can find strategies that are suitable for me to improve English-speaking skills. & $\begin{array}{l}\text { Before } \\
\text { After }\end{array}$ & $\begin{array}{l}42 \\
42\end{array}$ & $\begin{array}{l}3.69 \\
3.88\end{array}$ & $\begin{array}{l}0.680 \\
0.670\end{array}$ \\
\hline 9. I can set myself tasks to learn English-speaking skills. & $\begin{array}{l}\text { Before } \\
\text { After }\end{array}$ & $\begin{array}{l}42 \\
42\end{array}$ & $\begin{array}{l}3.21 \\
3.47\end{array}$ & $\begin{array}{l}0.812 \\
0.772\end{array}$ \\
\hline 10. I can set myself specific goals for learning English-speaking skills. & $\begin{array}{l}\text { Before } \\
\text { After }\end{array}$ & $\begin{array}{l}42 \\
42\end{array}$ & $\begin{array}{l}3.14 \\
3.64\end{array}$ & $\begin{array}{l}0.925 \\
0.655\end{array}$ \\
\hline Total & $\begin{array}{l}\text { Before } \\
\text { After }\end{array}$ & $\begin{array}{l}42 \\
42\end{array}$ & $\begin{array}{l}31.80 \\
35.50\end{array}$ & $\begin{array}{l}2.839 \\
2.432\end{array}$ \\
\hline Valid N & $\begin{array}{l}\text { Before } \\
\text { After }\end{array}$ & $\begin{array}{l}42 \\
42\end{array}$ & & \\
\hline
\end{tabular}

Item 2 concerning students' initiative to practice English-speaking skills with others had increased from 2.83 points before the experiment to 3.50 points after the experiment. The means of Item 7 concerning students' awareness of their own needs in learning English-speaking skills (before $\bar{x}=3.38$, after $\bar{x}=3.42$ ) and Item 5 concerning their ability to practice Englishspeaking skills on their own (before $\bar{x}=3.52$, after $\overline{\mathrm{x}}=3.57$ ) had comparatively slight improvement. These all indicate that students' sense of learner autonomy was promoted during the experiment. Moreover, their motivation in learning English-speaking skills was developed too.
As for the other items, they all had different levels of improvement. Most of them had a mean score higher than 3.5 points after the experiment except for item 3, item 7, and item 9. That is to say, after the experiment, students' agreements on the 7 items with a mean score higher than 3.5 points were generally high. Moreover, the mean of the total score had increased significantly from 31.80 points (out of 50) before the experiment to 35.50 points (out of 50) after the experiment $(\mathrm{p}=0.000)$. This indicates that students in the experimental group had improved their sense of learner autonomy significantly after the pedagogic intervention. 


\subsubsection{Semi-structured Interview}

A semi-structured interview with 10 leading questions was conducted with 13 students selected randomly from the experimental group to collect indepth information about students' perceptions of the pedagogic intervention and the development of their sense of learner autonomy. Among the 10 leading questions, Question number 1 "what do you think of autonomous learning?" and number 7 "From your perspective, what effects did the experiment have on you regarding learner autonomy development?" were designed to elicit interviewees' opinions of the effects the intervention had on developing their sense of learner autonomy.

Among the 13 interviewees, 7 considered the experiment as "very helpful" in improving their sense of learner autonomy, 4 considered it as "helpful", whereas 2 considered it as "somewhat helpful". They were then asked to describe in detail their understanding, experience, and feelings concerning learner autonomy during the experiment. One interviewee who reported "very helpful" said "We needed to perform a role play game in each lesson and we were given freedom in the first half of the lesson to use the Internet to learn in any places we liked. As a result, this kind of learning behavior became a habit of mine. I think autonomous learning means that students learn autonomously without requirement or restriction. I spent more time surfing the Internet to find interesting learning materials and make relevant study plans now. I think that means my sense of learner autonomy had strengthened because of the experiment. I rarely did anything related to learning English-speaking before."

Most of the interviewees who reported "very helpful" or "helpful" held similar opinions. They reported that they spent more time learning and practicing English-speaking skills or making other kinds of effort to improve their English-speaking skills without being required only because they enjoyed the ESC lessons and wanted to perform better in the lessons. Two interviewees mentioned that they thought it was because they had been given the freedom to learn in their own ways so that they could become more autonomous learners gradually, quoting one of the interviewee's statements "I think my learner autonomy has improved because now I can do things concerning the ESC lessons without teacher's requirement. I started to find different learning strategies from the Internet and try those seem to be suitable for me. I think it is because I often do this in the ESC lessons, I become used to it."

As for the two interviewees who considered the experiment as "somewhat helpful" in improving their sense of learner autonomy, both reported that they thought they had improved their sense of learner autonomy, but were not sure about how much. One reported that he thought the ESC lessons were more intense so that he had to spend more time and make more preparation after class in case that he couldn't catch up with his teammates during the role play game. The other reported that he was not very clear about what autonomous learning was but he believed that he had become more autonomous in learning English-speaking skills because during the experiment he often unconsciously did things related to the ESC lessons and English-speaking learning.

\subsection{How do the students perceive and react to the whole intervention?}

\subsubsection{Questionnaire}

The questionnaire concerning students' perceptions of the pedagogic intervention was administered to the experimental group students after the experiment. Like the questionnaire concerning learner autonomy, the questionnaire for students' perceptions and reactions used 5-point Likert-scale questions to elicit information. The scale also ranged from strongly disagree, disagree, undecided, agree, to strongly agree, to make clear distinctions between students' levels of agreement on the statements. To score the items, 1 point was assigned to strongly disagree, 2 to disagree, 3 to undecided, 4 to agree, and 5 to strongly agree. A higher score indicated students' stronger agreement with the corresponding item.

All the items on the Likert-scale had a mean higher than 3.5 except for item number 6 "I prefer the traditional way of teaching ESC than the experiment." which was a negative statement for the experiment ( $\bar{x}=1.83$ ). The students generally agreed that the experiment improved their English-speaking skills ( $x=3.81)$ and strengthened their confidence in learning English-speaking skills $(\bar{x}=3.71)$. They liked the way of teaching during the experiment ( $\bar{x}=4.21$ ), which was consistent with the low level of agreement on the statement that they preferred the traditional way of teaching $(\bar{x}=1.83)$. The students agreed that the experiment enhanced their sense of learner autonomy ( $x=3.95$ ), which was consistent with the findings from the questionnaire and the semi-structured interview concerning learner autonomy in the earlier section. They thought the experiment introduced them a better way to use technology devices to facilitate their study ( $\mathrm{x}=4.26$ ), and increased the chance of inter-student interactions ( $\bar{x}=4.24)$. Students considered having ESC lessons during the experiment as enjoyable ( $\mathrm{x}=3.83$ ), and they thought they became more interested in learning English-speaking skills because of the experiment $(\bar{x}=3.69)$. 


\subsubsection{Semi-structured Interview}

Among the 13 interviewees, 8 reported that they thought the ESC lessons during the experiment were "very effective" while the other 5 reported "somewhat effective". One interviewee stated that "I could notice that my English-speaking proficiency is getting higher and higher during the experiment, and some of my roommates too." Another interviewee said that taking part in the experiment a few weeks later, he started to feel less nervous and more confident when he talked to his classmates or teachers in English. The interviewees were then asked to describe in detail their opinions and feelings on the ESC lessons. Most of their answers contained commendatory words such as "innovative", "interesting", "fun", "enjoyable", and "interactive", etc. As one interviewee put it "I think the new ESC is very innovative, as the course in the universities of western countries. We were specially allowed to learn in our own styles, and we didn't need to go to the classroom in 45 minutes. Moreover, we were taught to use our mobile phones and computers to obtain useful information and resources, I think it is very useful in many other courses too. This should be applied to other courses."

Based on the interviews, the students were extremely keen on the first section of the lesson, where they were expected to practice what they learned in the IL training lesson. As one of them said, "Before, I used smartphone all the time but only for chatting and playing games. When I was shown many examples of using smartphones and computers to facilitate learning, I think it was amazing." Most of them also reported that they liked the ongoing role-play game as well. As for the reflection report, 2 interviewees reported that they would like to have detailed feedback from the teacher about what they wrote on the reports. All the interviewees showed positive attitudes toward the intervention overall. Nonetheless, just as every coin has two sides, not all the students liked the intervention from the beginning. One interviewee reported that he thought the intervention was very intense, so that he had to spend more time in preparation just in case that he couldn't catch up with his teammates in the role play game section and embarrassed himself. Yet, he also admitted that this "anxiety" made him learn harder and progress faster.

Most of the interviewees thought that the traditional ESC lessons were more relaxing and easier than the ESC lessons during the experiment. However, they all agreed that the experiment was better for learning to speak English effectively. Quoting one interviewee's words, "The traditional ESC was very relaxing. We didn't need to prepare anything before the lesson, and the teacher promised us at the beginning that none of us would fail this course. The experiment was more stressful since we needed to perform ongoing role- play games in front of our classmates and teachers in every lesson. We inevitably needed to think more about how to act in the role play game and how to get suitable information and resources. However, I liked the experiment more than the traditional ESC because it was interesting and challenging. I think a more serious but also more interesting learning pattern can push me to learn more."

Six interviewees mentioned that they had problems during the experiment, and all their problems were related to the uncertainty and unfamiliarity with the experiment. They often felt unsure of what they were doing at the beginning of the experiment. As one interviewee put it, "In the first and second lesson, I was confused by the strange approach, and I was not sure whether I understood the routines of each lesson." Within two or three weeks, students started to enjoy the experiment. Another interviewee said, "The problems were solved in the second week when I saw what my classmates were doing. I started to understand the characteristics and purposes of the lessons." These findings are consistent with the findings from the questionnaire.

When the interviewees were asked whether they had troubles during the intervention or any suggestions for this experiment, 6 interviewees mentioned that they were confused by the new routines and not sure about what they were supposed to be doing at the beginning of the intervention. Nonetheless, given some time, they started to enjoy the new routines and realized that they got benefits from them. As one interviewee said "The problems were solved in the second week when I saw what my classmates were doing. I started to understand and like the characteristics of the lesson. A little stress made me work harder and learn better." As for the suggestions, 2 interviewees indicated that it would be much better if the teacher could give feedback on the reflection reports, and 3 wanted in-depth feedback on their role play game performance. As one of them put it "I really want to know whether the information and resources I used are useful or not and whether my ideas are good or not." Another interviewee said that "The feedback we gained was very little. I think the teacher should give us more feedback on each students' performance." Another interviewee suggested that instead of being assigned a role in the role play game task, the students should be the ones to choose the roles they like. In that case, they would be more interested in playing the game.

\section{IMPLICATIONS FOR PEDAGOGY}

Based on the questionnaire and interview, both the students and teachers involved in the current study showed positive attitudes toward this approach. The study's findings are sufficiently compelling to suggest 
the necessity of reforming the current ESC in China on the basis of the new approach used in the intervention. As the approach was specifically designed for ESC, the application of it in ESC classrooms should not in any way conflict with the current context of Chinese higher education, although Task 1, where students were set free to collect learning resources and information from wherever they liked, might seem like a challenge to the traditional classroom and face-to-face teaching and learning. Nonetheless, it would not affect the authority of classroom discipline since the ESC classroom led by the NSE teachers has always been more flexible, more recreational, and less test-dominated (the speaking skill as the foremost course objective of the ESC, is not included in most of the national tests for English proficiency). Consequently, it is not unusual for the NSE teachers to bring the students out of the classroom and play games outdoor. In other words, this Task does not violate the existing educational system. Therefore, it can be applied to the ESC classroom directly without the extra effort of applying for permission from the institutes or the local board of the Ministry of Education.

Besides applying the intervention to reform ESC classrooms on a national scale, teachers and other stakeholders, such as educators, government, and educational policy-makers, should rethink the whole EFL education in China in relation to the intervention in the current study. This is especially the case for educators and educational policy-makers who are directly relevant to education and have the power to influence EFL education on a national scale directly. They need to consider at least three things based on the current study. The first is to rethink the role of speaking in EFL education in China. The educators and educational policy-makers should rethink the amount of attention that should be given to speaking under the core purposes of EFL education in different levels of school (from primary school to college) and its practice in the current context of China. After that, instead of general curricula, clear and detailed EFL curricula should be developed for different levels of schools, and the action should be taken (such as embedding speaking in all kinds of English proficiency tests) to ensure the implementation of the curricula. In this case, it can prevent the schools and teachers from finding a way to perfunctorily walk through teaching routines.

The second is the necessity to develop students' sense of learner autonomy and their awareness of information and technology convenience. As it is widely recognized that we are in an era of overabundant information and convenient technology, which can present crucial challenges as well as opportunities that formal education and students of all levels face today [8]. Educators and educational policy-makers should research the situations and contexts regarding information and technology convenience and the possible effects they could or would have in education. With a better understanding of the background and environment of fast information and convenient technology, we can, therefore, face the challenges brought from them and turn them into opportunities. Since the trend of fast information and convenient technology is unstoppable, they should figure out a way to embed the development of learner autonomy and information literacy skills into curricula at all levels of schooling accordingly. In so doing, they are preparing the students for an age of uncertainty because these are the foremost skills or qualities one needs to pursue lifelong learning and make better decisions. As Šorgo et al. [12] suggest, a broad spectrum of information literacy skills promotes higher cognitive levels of thinking and more systematic learning. Higher cognitive levels of thinking and systematic learning naturally lead to better classroom performance and lifelong learning.

The last point to be made is the potential of the approach in different courses, subjects, and contexts. The results and findings indicated the effectiveness of the approach to ESC teaching and learning and its potential in developing students' sense of learner autonomy as well as raising their awareness of information and technology convenience. Moreover, the students generally had positive attitudes toward the approach and suggested in the interview that the approach had the potential to be widely applied to other courses. As a result, educators, educational policymakers, and relevant researchers should consider conducting replication studies on a larger scale to test the validity and generalizability of the present findings in other courses or other educational contexts.

\section{CONCLUSION}

The present study was conducted to examine the effects of the new approach for ESC on improving Chinese undergraduate students' English-speaking skills and their sense of learner autonomy and to investigate the students' perceptions of this approach. The findings showed that students in the experimental group improved their English-speaking skills and sense of learner autonomy significantly after 11 weeks of pedagogic intervention. They outperformed students in the control group in terms of English-speaking skills and learner autonomy after the experiment. However, students in the control group did not make significant improvements in English-speaking skills in general nor significant improvements in students' sense of learner autonomy during the 11 weeks. Consequently, the intervention was more effective in achieving course objectives and optimizing classroom effectiveness than the traditional ESC classroom. Students in the experimental group had positive attitudes toward the intervention in general. They found the experience of 
having ESC lessons during the experiment challenging, motivating, and enjoyable. They indicated that a certain amount of pressure in the experiment helped them improve their English-speaking skills faster and strengthened their sense of learner autonomy as well. They considered the new approach to be effective, and they suggested that it could be applied to other courses if possible. Nonetheless, they also indicated that the approach could be better if the NSE teacher could give them in-depth feedback on their performance in the role play game and the reflection reports they wrote.

\section{REFERENCES}

[1] F. Pawan, W. Fan, P. Miao, Teacher Training and Professional Development of Chinese English Language Teachers: Changing from Fish to Dragon. Taylor \& Francis. (2017).

[2] X. He, X. Zhang, Learning English: high cost, low productivity. China News Weekly, 45 (2005) 019 (In Chinese).

[3] W. Tang, Y. D. Zhu, Y. Zhou, L. Li, A Study of the Problems in the Classrooms of Oral English for Non-English-Major Students Conducted by English Native Speaking Teachers [J]. Journal of Guangdong University of Foreign Studies, 6 (2008) 025 (In Chinese).

[4] Y. Zhang. Study on the Current Teaching Situation of Foreign Teachers' in on-English Major College Students' English Classes: Based on Three Universities in Dalian. Master's thesis, Liaoning Normal University, Dalian, China. (2013).

[5] Z. Xiao, Analysis on the characteristics and existing problems of Foreign Teachers' teaching of English Speaking Course. English Square: Academic Research, 12(6) (2012) 71-73. (In Chinese)

[6] W. Wen, Analysis on the characteristics and existing problems of Foreign Teachers' teaching of English Speaking Course. Time Education, 16(8) (2016) 111-111 (In Chinese).

[7] P. Hubbard. Making a case for learner training in technology enhanced language learning environments. Calico Journal, 30(2) (2013) 163178.

[8] P. S. Breivik. 21st century learning and information literacy. Change: The Magazine of Higher Learning, 37(2) (2005) 21-27.

[9] S. Campbell. 'Defining information literacy in the 21st century', in World Library and Information Congress: 70th IFLA General Conference and Council, IFLA, Buenos Aires, Argentina. (2004).
[10] L. Feng, J. L. Ha, Effects of Teachers' Information Literacy on Lifelong Learning and School Effectiveness. Eurasia Journal of Mathematics, Science \& Technology Education, 12(6) (2016).

[11] X. Shao, G. Purpur, Effects of information literacy skills on student writing and course performance. The Journal of Academic Librarianship, 42(6) (2016) 670-678.

[12] A. Šorgo, T. Bartol, D. Dolničar, B. Boh Podgornik, Attributes of digital natives as predictors of information literacy in higher education. British Journal of Educational Technology, 48(3) (2017) 749-767.

[13] A. Lian, M. V. Pineda, Rhizomatic learning: "As... when... and if..." A strategy for the ASEAN community in the 21st century. Beyond Words, 2(1) (2014) 1-28.

[14] H. Liu, W. Qi, Establishing Learner Autonomy in China's Universities through Achievement Presentation. Journal of Language Teaching and Research, 8(3) (2017) 588-593.

[15] A. Kukulska-Hulme, H. Lee, L. Norris, Mobile Learning Revolution: Implications for Language Pedagogy. In: Chapelle, Carol A. and Sauro, Shannon eds. The Handbook of Technology and Second Language Teaching and Learning. Oxford: Wiley \& Sons, (2017) 217-233.

[16] M. B. Eisenberg. Information literacy: Essential skills for the information age. DESIDOC journal of library \& information technology, 28(2) (2008) 3947.

[17] A. P. Lian, M. C. Mestre, Goal-directed communicative interaction and macrosimulation. Revue de phonétique appliquée, 73 (1985) 74-75.

[18] É. Illés, S. Akcan, Bringing real-life language use into EFL classrooms. Elt Journal, 71(1) (2017) 312.

[19] M. G. Tassinari, Evaluating learner autonomy: A dynamic model with descriptors. Studies in SelfAccess Learning Journal, 3(1) (2012) 24-40.

\section{Biodata}

Kezhen Liu is an M.A. student in Suranaree University of Technology, Thailand. She studies under the supervision of Professor Dr. Andrew Lian and Dr. Butsakorn Yodkamlue. Meanwhile, she is a primary school English teacher in China. Her research interests include learner autonomy, English-speaking, Technology-enhanced Language Learning 